\title{
Believed effect - A prerequisite but not a guarantee for acceptance of carnivore management interventions
}

\author{
Ann Eklund $^{\mathrm{a}, *}$, Maria Johansson ${ }^{\mathrm{b}}$, Anders Flykt ${ }^{\mathrm{c}}$, Henrik Andrén ${ }^{\mathrm{a}}$, Jens Frank ${ }^{\mathrm{a}}$ \\ ${ }^{a}$ Grimsö Wildlife Research Station, Department of Ecology, Swedish University of Agricultural Sciences, SE-730 91 Riddarhyttan, Sweden \\ ${ }^{\mathrm{b}}$ Environmental Psychology, Department of Architecture and Built Environment, Lund University, Box 118, SE-221 00 Lund, Sweden

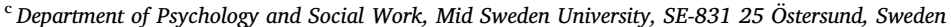

\section{A R T I C L E I N F O}

\section{Keywords:}

Large carnivore

Predation

Conflict mitigation

Human perceptions

Potential for conflict index

Wildlife conflict

\begin{abstract}
A B S T R A C T
Conflicts over wildlife and their potential impacts on human practices and livelihoods are widespread. Large carnivore predation on livestock often becomes a contested topic which has led to global declines in carnivore numbers over centuries. To minimise impacts of carnivores on human livelihoods and allow conservation, various interventions are used to prevent attacks. However, these interventions can only be effective if they are used and implemented. According to the Technology Acceptance Model, end user acceptance depends on perceived usefulness and ease of use. This study investigates the former as believed effect through a modified version of the Potential for Conflict Index. Using a web-based questionnaire we assess acceptance levels and believed effect of interventions intended to prevent carnivore predation on livestock, dogs, and reindeer among animal owners/keepers and members of the public in Sweden. The analysis shows that believed effect is a prerequisite for acceptance of an intervention, but not a guarantee. Interventions promoted by authorities are in some cases highly acceptable to users and the public, but in other cases believed contra-productive and are opposed by the end users. Active promotion of the latter may undermine mitigation efforts. Carnivore removal is generally more acceptable to animal owners than to members of the public. The results are useful to minimise conflicts within carnivore management and increase transparency and success of conservation. The results are discussed in relation to how similar questions may be approached in other systems using combined measures of believed effect, accept-intention, and the Potential for Conflict Index.
\end{abstract}

\section{Introduction}

Conflicts over wildlife and their potential impacts on human practices and livelihoods are widespread as a result of human advancement into wilderness areas (e.g. Okello, 2006), wildlife population range expansion (e.g. Gompper, 2002), or wildlife recovery due to successful conservation (e.g. Fox and Madsen, 2017; Westerberg et al., 2006). Globally, these conflicts involve various types of wildlife ranging from large grazing animals such as elephants (e.g. Williams et al., 2001; Tchamba, 1996), to migratory birds (e.g. Eythórsson et al., 2017; Fox and Madsen, 2017; MacMillan et al., 2004), and marine animals (e.g. Westerberg et al., 2006; Wickens et al., 1992). Terrestrial large carnivores represent a wildlife guild of high conservation priority that can impact human life and practices through the predation on domestic animals. Consequently, a variety of interventions intended to prevent predation are promoted as important tools of carnivore management and conservation worldwide (Treves and Karanth, 2003; Shivik, 2006).
Interventions are often promoted by managers and conservationists to be used by owners of livestock and pets (hereafter interchangeably referred to as "animal owners", "owners", or "users" of interventions). However, the interventions can provide a reduction in predation and human anxiety only if they are accepted and used by the animal owners, who are the end-users of interventions. The interventions may have the additional potential to mitigate conflicts between people with interest in conservation and those with interest in domestic animal husbandry, but knowledge about user perceptions of interventions is essential for successful implementation (Redpath et al., 2015; Riley et al., 2002). If interventions are implemented without the support of the users or the public, the process can become problematic and increase segregation between stakeholder groups (Bruskotter et al., 2007; Riley et al., 2002), and in turn challenge human-carnivore coexistence (Højberg et al., 2017). For a transparent and informed use of interventions, it is important to gain knowledge about the general tendencies of acceptance for or opposition against interventions among

\footnotetext{
* corresponding author.

E-mail address: ann.eklund@slu.se (A. Eklund).
} 
stakeholders as well as members of the public (Gigliotti et al., 2000). Interventions with high acceptability may be more suitable for large scale implementation and for further evaluations with regards to their effectiveness in reducing losses of domestic animals, needed to expand the currently limited evidence base (van Eeden et al., 2018; Eklund et al., 2017; Treves et al., 2016). Understanding of acceptance levels is also important to identify potential conflict over intervention use, as conflict can occur between people who do not share similar views on which interventions are acceptable and which are not (Redpath et al., 2015; Vaske et al., 2010).

Acceptance of interventions relates to acceptance of impact mitigation techniques and can be reported along a scale ranging from acceptance to opposition (Gigliotti et al., 2000). The acceptance of technological solutions has been described using the Technology Acceptance Model (TAM) (Davis, 1989) and hypothesises that user acceptance is determined by the perceived usefulness and the perceived ease of use of the technology. Perceived usefulness is defined by Davis (1989) as "the degree to which a person believes that using a particular system would enhance his or her job performance" and relates to the definition of useful as "effective; helping you achieve something" (Cambridge Dictionary online: dictionary.cambridge.org). This definition links perceived usefulness to believed effect which this study investigates in relation to acceptance levels. The perceived ease of use (Davis, 1989) is defined as "the degree to which a person believes that using a particular system would be free of effort" based on the dictionary definition of the word ease, "freedom from difficulty, effort, or pain" (Cambridge Dictionary online: dictionary.cambridge.org).

Our focus is on interventions that are commonly used or suggested to animal owners for protecting their domestic animals from large carnivores. The aim is to investigate how interventions are perceived by the animal owners with the TAM as a framework for discussion about the relationship between acceptance and believed effect. Further, we aim to investigate potential conflict over intervention use between animal owners and members of the public. More specifically, in this study we aim to answer the questions: 1 ) What are the general tendencies of opposition or acceptance for interventions? 2) What are the general tendencies of believed effect for interventions? 3) To what extent is the intention to oppose or accept interventions related to the believed effect of the intervention? 4) Is there high dispersion in the intention to oppose or accept interventions and thereby a potential for conflict over intervention use within owner groups, and in comparison to members of the public?

\section{Material and methods}

\subsection{Study area}

Our study was undertaken in Sweden, where recovering large carnivore populations of wolves (Canis lupus), lynx (Lynx lynx), brown bears (Ursus arctos), and wolverines (Gulo gulo) represent the four terrestrial mammalian large carnivore species (hereafter carnivores for simplicity), that occasionally or regularly predate on domestic animals. The approximate species distribution range can be viewed in Figure A1. We identified the main animal owner groups from the annual statistics of carnivore attacks on domestic animals, published by the Swedish Wildlife Damage Centre (Frank et al., 2018). These groups were sheep owners, transhumance farmers, hunters with dogs and owners of pet dogs. Sheep in Sweden are generally fenced, whereas transhumance farmers keep livestock free ranging in the forest during the summer. During hunts dogs are traditionally loose, whereas pet dogs can be on or off a leash. An additional group, reindeer herders, were also included in the study. The herders own and manage free roaming semi-domestic reindeer in the northern half of Sweden, and the reindeer represent the main prey for carnivores in the northern regions (Pedersen et al., 1999; Mattisson et al., 2011 and 2016).

\subsection{The questionnaire}

We collected data by means of a questionnaire. To collect data on oppose-accept intention (OA) and believed effect (BE) we developed items for each intervention in each sample (see Table A1 for all items). The OA items and BE items followed either of two formats, and responses were given on a 5-point Likert scale, shown in Table 1. For each intervention there was a possibility for respondents to comment in a free text response.

\subsection{Included interventions}

Various types of interventions with different functional properties were included in the study. Table A2 reveals which specific interventions were proposed to which user groups, and Table 2 give detail of their intended functions. Reindeer herders, sheep owners, and hunters with dogs were asked to respond to $\mathrm{OA}$ and $\mathrm{BE}$ items of 10 different interventions, transhumance farmers of 9 interventions, and pet dog owners of 12 interventions to prevent carnivore attacks on their animals. Members of the public were asked about 8 different interventions in relation to the protection of the various different animals. The included interventions were decided by the research group, and only interventions already in use or those available for use were included. The proposed mechanism behind the intervention should be considered realistic in Swedish conditions. The interventions proposed to members of the public were deemed likely to influence this group by hindering movement, creating disturbance, or by being norm incongruent.

\subsection{Procedure}

We used a Qualtrics web-survey, which was distributed via a link through different communication channels (Table 3). Animal owners were registered with the Swedish Kennel Club (dogs) and the Swedish Board of Agriculture (sheep and transhumance farming) from where email, or postal, addresses were obtained. The Swedish Sheep Breeders Association also assisted with the distribution of the survey to sheep owners. The survey was distributed via email to 48 reindeer herding districts with email addresses listed on the Sami Parliament website (www.sametinget.se) and forwarded to active herders. Due to this intermediary step in distribution, it was not possible to record how many links were finally distributed to reindeer herders. The project was approved by the ethical board in Uppsala, Sweden, (Dnr 2017/259) before distributing the link to reindeer herders ${ }^{1}$. To get a representative sample from the Swedish public, we purchased 1000 responses from Norstat sampling firm. We also approached the Swedish Carnivore Association and the Swedish Society for Nature Conservation for distribution of the survey to their members, but both non-governmental organisations turned down our request.

Respondents in all groups should be at least 18 years of age. The number of returned surveys was 1155 (87\%) from hunters with dogs, 229 (26\%) from pet dog owners, 57 from reindeer herders (unknown response rate due to unknown number of delivered surveys), 472 (30\%) from sheep owners, and 88 (40\%) from transhumance farmers. For the analysis in this study we included only the returned surveys where all items for Oppose-Accept and Believed Effect (see Table A1) were completed. The number of completed surveys and response rates for $\mathrm{OA}$ and BE items are shown in Table 3.

\subsection{Data analysis}

For each intervention and user group, we calculated the general OA

\footnotetext{
${ }^{1}$ Reindeer herders are mainly part of the Sami community, which is a minority ethnic group in Sweden. Ethical permission was sought to include this group in our study.
} 
Table 1

$\mathrm{OA}$ and $\mathrm{BE}$ items proposed to animal owners and members of the public. OA items and BE items were formulated according to either of the two formats $\mathrm{A}$ or $\mathrm{B}$ for animal owners, depending on the character of the intervention in question. Members of the public responded to the same BE items as animal owners, and OA item C. Responses were given on a 5-point Likert scale, coded as numerical values from -2 to 2 for analysis.

\begin{tabular}{|c|c|c|}
\hline \multirow[t]{2}{*}{ BE items } & A & How well do you believe that intervention work to protect domestic animal from large carnivore attacks \\
\hline & B & How well do you believe that intervention work to protect domestic animal from being killed/injured at the event of a large carnivore attack \\
\hline \multirow[t]{5}{*}{ Response options (BE) } & -2 & Can substantially increase the risk of an attack / that animals are killed/injured during an attack \\
\hline & -1 & Can somewhat increase the risk of an attack / that animals are killed/injured during an attack \\
\hline & 0 & Does not influence the risk of an attack / that animals are killed/injured during an attack \\
\hline & 1 & Can somewhat reduce the risk of and attack / that animals are killed/injured during an attack \\
\hline & 2 & Can substantially reduce the risk of an attack / that animals are killed/injured during an attack \\
\hline \multirow[t]{3}{*}{ OA items } & A & Which is your stand on using intervention with the purpose to protect your animal from being attacked by large carnivores? \\
\hline & B & Which is your stand on using intervention with the purpose to protect your animal from being killed/injured at the event of a large carnivore attack? \\
\hline & $\mathrm{C}$ & Which is your stand on intervention being used in Sweden, with the purpose to protect animal from being attacked by large carnivores? \\
\hline \multirow[t]{5}{*}{ Response options (OA) } & -2 & I definitely oppose \\
\hline & -1 & I likely oppose \\
\hline & 0 & I do not care \\
\hline & 1 & I likely accept \\
\hline & 2 & I definitely accept \\
\hline
\end{tabular}

Table 2

Description of interventions.

\begin{tabular}{|c|c|c|}
\hline Intervention type & Intervention & Description \\
\hline \multirow[t]{10}{*}{ Avoiding encounters } & Increased surveillance & Longer visits or larger number of visits to the livestock/reindeer herds. \\
\hline & More people & $\begin{array}{l}\text { More eyes and increased surveillance of hunting dogs and pet dogs during hunting or exercise, and gives a } \\
\text { better chance of observing carnivore that move into the area where dogs are released. }\end{array}$ \\
\hline & Search for tracks & $\begin{array}{l}\text { If no carnivore tracks in snow/sand are found it could indicate that no carnivores have entered the area into } \\
\text { which domestic animals are released. }\end{array}$ \\
\hline & Ban bait site & To reduce the risk of attracting carnivores to the area into which domestic animals are released. \\
\hline & Move reindeer & Reindeer moved to areas with lower carnivore prevalence may be able to avoid carnivores. \\
\hline & Dogs on leash & Pet dogs that are kept on a leash cannot search out carnivores. \\
\hline & Increase dog training & Hunting dogs that only follow the target wildlife species, and do not search out carnivores. \\
\hline & Anti-hunt training & Pet dogs are trained to not follow or search out wildlife. \\
\hline & Recall training & Dogs can be kept at a shorter distance from the owner to reduce the likelihood for carnivore encounters. \\
\hline & Change dog breed & $\begin{array}{l}\text { Breeds that stay closer to the owner or has a larger body mass may be less likely attacked or killed by } \\
\text { carnivores. }\end{array}$ \\
\hline \multirow[t]{6}{*}{ Barriers } & Carnivore deterring fences & $\begin{array}{l}\text { Fences of either five live wires or a combination of nets and live wires to reduce the risk of carnivore entering a } \\
\text { livestock enclosure. }\end{array}$ \\
\hline & Night shelter & Domestic animals are kept in a barn or corral at night, when carnivores are most active. \\
\hline & Calving in enclosure & Prevents carnivores attacking reindeer calves when they are most vulnerable to predation. \\
\hline & Protective collar & Prevent lethal neck bites from carnivores on livestock. \\
\hline & Vest with spikes & Sharp spikes along the back of the dog prevent lethal carnivore bites. \\
\hline & Electric vest & Pressure triggered electric wires along the back and sides of the dog prevent lethal carnivore bites. \\
\hline \multirow[t]{7}{*}{ Deterrents } & $\begin{array}{l}\text { Light and sound deterrents/make } \\
\text { noise }\end{array}$ & $\begin{array}{l}\text { Motion triggered sound alarms or blinking lamps placed around livestock herds/pet dog owners make noise } \\
\text { during dog exercise. }\end{array}$ \\
\hline & Fladry & Cloth flags attached to a rope placed around the livestock herd to deter neophobic carnivores, such as wolves. \\
\hline & Light fires & Fires are lit around the reindeer herd to deter carnivores from approaching. \\
\hline & Eye spots & Artificial self-mimicry on reindeer hind parts to deter carnivores from attacking. \\
\hline & Bell & A bell on the collar creates a high pitch sound to deter carnivores from dogs. \\
\hline & More dogs & Release a group of dogs instead of a lone dog to make carnivores wary to approach. \\
\hline & Hazing of carnivores & Deter carnivores from approaching or moving into reindeer herds using snow mobiles. \\
\hline \multirow[t]{2}{*}{ Livestock guarding animals } & Livestock guarding dog & Alert humans to the presence of carnivores and may have a deterring effect on approaching carnivores. \\
\hline & Livestock guarding llamas & Actively protect the livestock herd from approaching carnivores. \\
\hline \multirow[t]{3}{*}{ Removal } & Selective removal & Carnivore hunting targeting a specific "problem individual" that has caused problems with domestic animals. \\
\hline & Zoning & $\begin{array}{l}\text { Carnivore hunting targeting all individuals in a predefined geographical area to remove the risk of carnivore } \\
\text { encounters in the area. }\end{array}$ \\
\hline & Proportional removal & $\begin{array}{l}\text { Carnivore hunting where a predefined proportion of the carnivore population is removed to reduce the overall } \\
\text { risk of carnivore encounters. }\end{array}$ \\
\hline
\end{tabular}

and BE tendencies and second generation PCI as described by Vaske et al. (2010) using the analysis sheet available from https://sites. warnercnr.colostate.edu/jerryv/potential-conflict-index/. The resulting $\mathrm{PCI}_{2}$ values for $\mathrm{BE}$ and $\mathrm{OA}$ were used to create modified bubble charts, adapted to allow communication of the two variables in relation to one another, in R Plotrix package (Lemon, 2006). The charts illustrate the mean accept-intention in a sample as well as the consent or dissent within or between sample populations (Manfredo et al., 2003). The maximum Potential for Conflict occurs when responses are equally distributed at the two extremes which generate a PCI value of 1 . A PCI value of 0 is reached when there is no variability in responses. The PCI value is illustrated as the size of a bubble in a bubble graph, and the position of the bubble on the axis indicates the central tendency of how an intervention may be received by the response group (Manfredo et al., 2003). The analysis has previously been used to inform wildlife management and policy of attitudes and acceptance for actions targeting a broad variety of wildlife management challenges, including the management of chronic wasting disease (Vaske et al., 2006; Needham et al., 2004), reducing human fear of bears and wolves (Frank et al., 2015), management of invasive alien species (Sharp et al., 2011), removal of native carnivores to increase game populations for hunting (Teel and Manfredo, 2010), and to investigate wildlife professionals' believed effect of carnivore management interventions (Lute et al., 2018).

To address our need to control for the believed effect when studying animal owners' acceptance of interventions, we combine the calculated PCI for acceptance on the Y-axis, with the PCI for believed effect on the 
$\mathrm{X}$-axis. Graphically, the result is illustrated as an ellipse or circle with a $\mathrm{Y}$-diameter that corresponds to the PCI value for $\mathrm{OA}$, and an X-diameter that corresponds to the PCI value for $\mathrm{BE}$. This allows us to investigate the relationship between the dispersion in acceptance and the dispersion in believed effect that animal owners express with regards to each specific intervention. It also illustrates where implementation of interventions could be difficult due to lacking acceptance. The position of the ellipse represents the coordinates of the central tendency for each parameter. In the diagram interventions in quadrant I (upper right) are to a larger extent accepted by the stakeholder group and are also believed to have a positive effect in reducing carnivore predation on the domestic animals. Interventions in quadrant II (upper left) are accepted although their function is believed to increase carnivore predation on the domestic animals, and interventions in quadrant III (lower left) are opposed and believed to increase carnivore predation. Interventions that are found in quadrant IV (lower right) are believed to effectively reduce carnivore predation but are opposed by the users.

\section{Results}

\subsection{Hunters with dogs}

Hunters with dogs expressed their highest acceptance for the three different removal interventions, that all averaged higher on acceptance than on the believed effect (Fig. 1a, Table A4). For all other interventions, the relationship was reversed (Fig. 1a, Table A4). Electric vests and vests with spikes scored on similar BE levels as the removal interventions, but generated a higher PCI for OA, and had a central tendency of OA which was lower than all removal interventions. Tracking carnivores before releasing the dog was believed to be only slightly less effective than the two vests, but had a higher central tendency for OA. The most strongly opposed intervention was changing dog breed, although it was believed to have some effect in reducing the risk of carnivore attacks. Using a bell to deter carnivores from attacking the dog was also opposed by hunters, and this intervention was believed to be counterproductive in preventing carnivore attacks.

\subsection{Pet dog owners}

The most acceptable interventions to pet dog owners were recall training, making noise, keeping the dog on a leash, exercising the dog in the company of more people, and anti-hunt training (Fig. 1b, Table A4). Keeping the dogs on a leash and making noise were also believed to be the most effective interventions to prevent carnivore attacks on pet dogs. The three interventions with focus on removing carnivores were less acceptable, and they also rendered the highest potential for conflict on the OA scale. Using a bell to deter carnivores from attacking the dog, or changing for a dog breed less prone to attacks, were believed to be the least effective interventions. These interventions were also less acceptable or even opposed by pet dog owners. Opposition was greatest toward changing to a larger dog breed to prevent carnivore attacks.

\subsection{Reindeer herders}

Among reindeer herders the highest average acceptance and believed effect was expressed for the three carnivore removal interventions (Fig. 1c, Table A4). Increased supervision and hazing of carnivores were also considered acceptable and somewhat effective. Moving reindeer and calving in enclosures were the interventions with the highest potential for conflict, followed by lighting fires around the herd. Although these interventions were considered somewhat effective, they were opposed. Using protective collars on the reindeer or painting eyespots on their hind quarters where believed ineffective interventions. These interventions were opposed by the herders. 

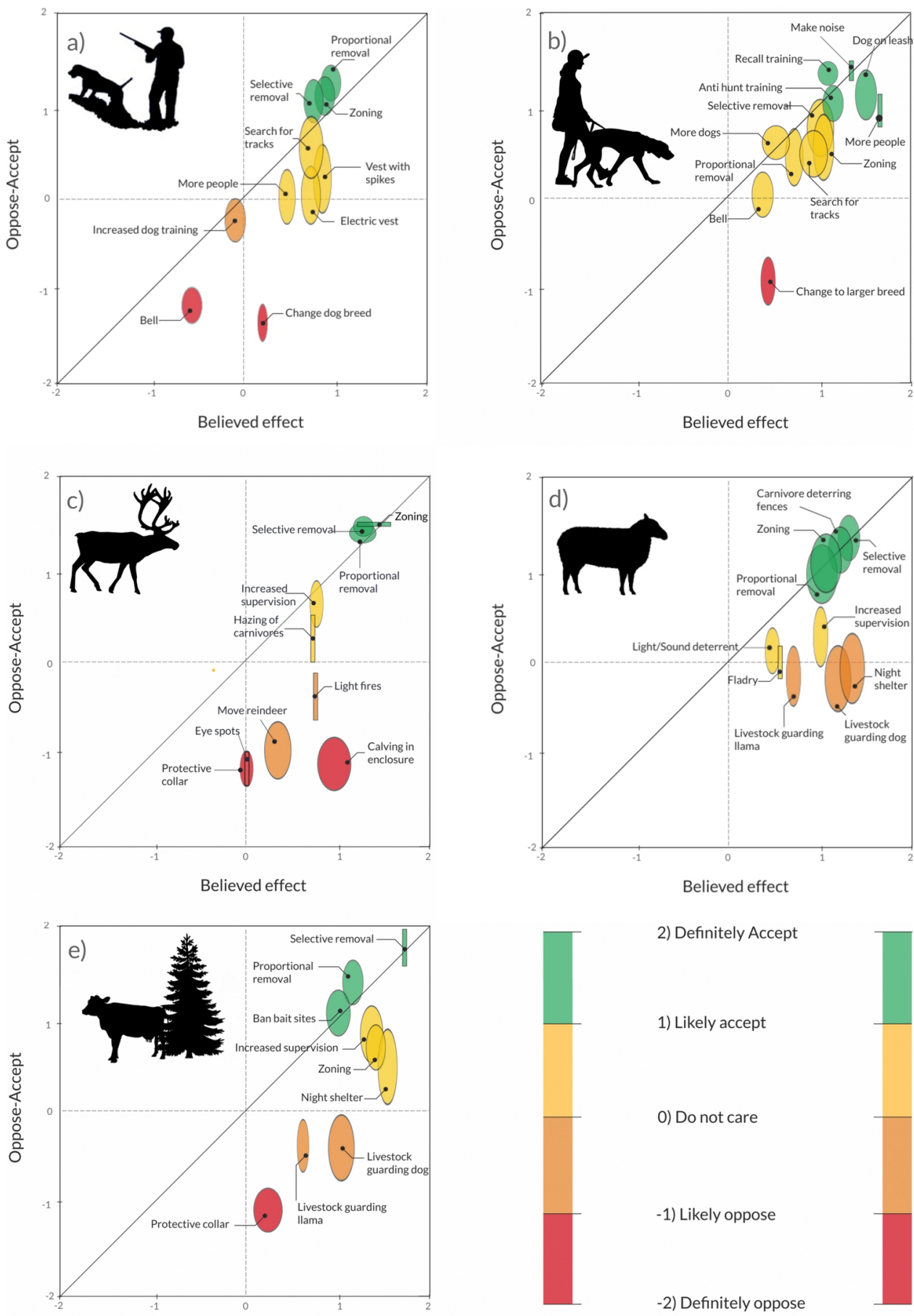

Believed effect

\subsection{Sheep owners}

Among sheep owners the three removal interventions and carnivore deterring fences were the most accepted interventions, and the acceptance levels for these interventions corresponded closely to what would be expected from their believed effect (Fig. 1d, Table A4). Most acceptable was the selective removal of "problem individuals", an intervention that also had a high believed effect, and low potential for conflict. The second most acceptable intervention was carnivore deterring fences, followed by zoning, and proportional removal of carnivores. Sheep owners believed all suggested interventions to be somewhat effective in reducing carnivore attacks on sheep. The intervention believed most effective was to keep the sheep in night shelters, but the
-1) Likely oppose
-2) Definitely oppose
2) Definitely Accept

1) Likely accept

0) Do not care (
Fig. 1. The graphs illustrate the central tendencies and potential for conflict among animal owners with regards to their opposition or acceptance and the believed effect of interventions intended to protect their animals from carnivore attacks. The owner groups are a) hunters with dogs, b) pet dog owners, c) reindeer herders, d) sheep owners, and e) transhumance farmers. Each bubble represents a specific intervention, the bubble diameter on the Y-axis the PCI for opposition-acceptance of that particular intervention within the stakeholder group. The bubble diameter on the $\mathrm{X}$ axis shows the PCI for the believed effect of that particular intervention within the stakeholder group. Green bubbles indicate a general acceptance tendency from 1 to 2 , yellow bubbles indicate a general acceptance tendency from 0 to 0.99 , orange bubbles indicate a general acceptance tendency of -1 to -0.01 , and red bubbles indicate a general acceptance tendency from -2 to -1.01 . Exact values can be viewed in Table A4. 


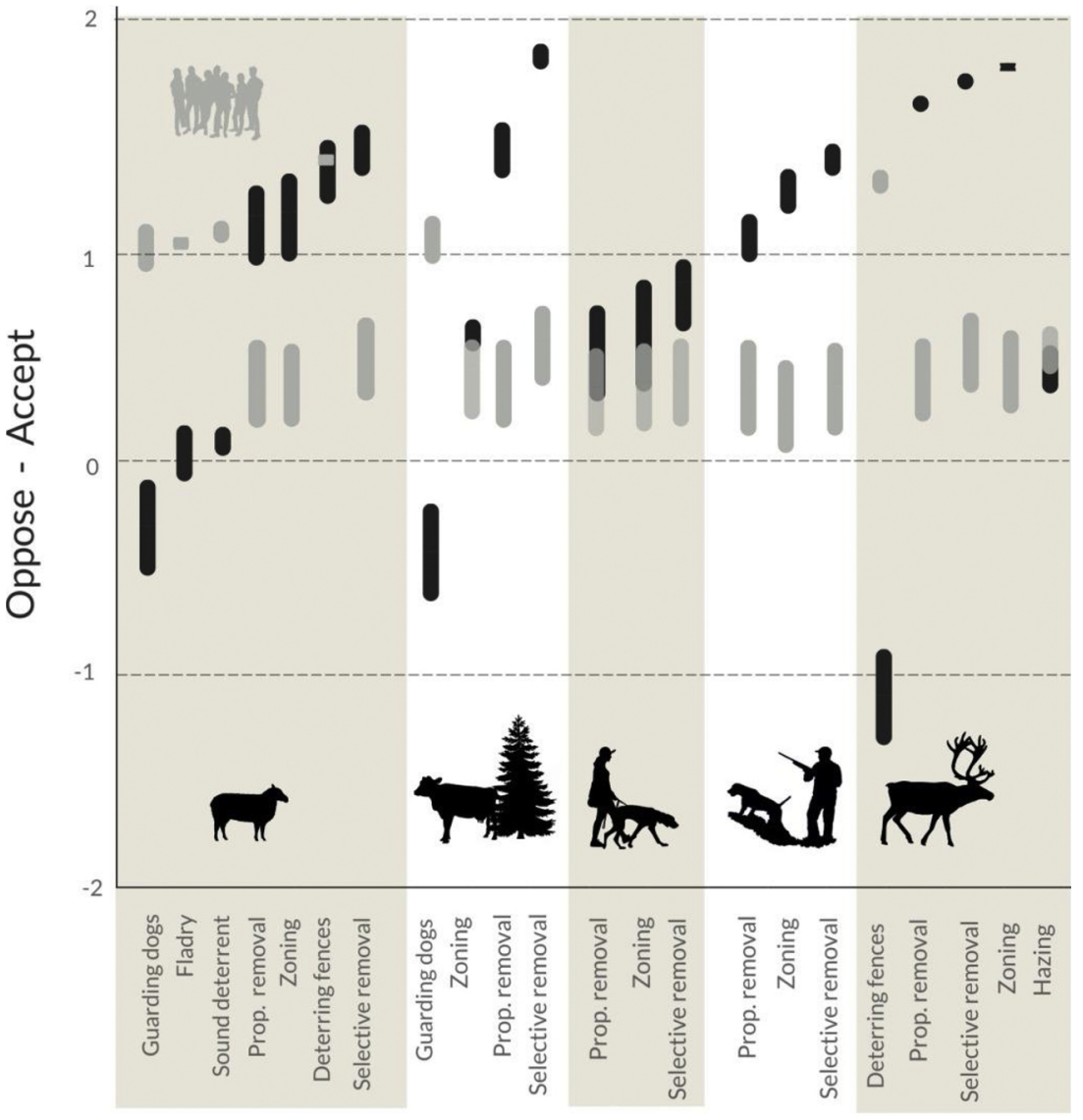

Fig. 2. Grey bars illustrate the Potential for Conflict Index for members of the public over the use of various interventions intended to prevent carnivore attacks on specified domestic animals. The black bars illustrate animal owner responses to the corresponding interventions. The bars' vertical centre point indicates the general tendency for acceptance of the intervention within each sample. The PCI value is indicated by the height of the bar, and exact values can be viewed in Table A4. conflict on both OA and BE scales, and was not believed to be as effective, but also scored relatively high on acceptance. In contrast, zoning was believed to be more effective than the proportional removal, but had a central tendency that was lower on the OA scale. Keeping animals in a night shelter was believed effective, but generated a high PCI on the OA scale, with a central tendency much lower than the three removal interventions. The night shelter was also less accepted than increased supervision and banning of bait sites, although these interventions were believed less effective than night shelters. Protective collars on livestock followed by livestock guarding dogs, and livestock guarding llamas, were generally opposed by transhumance farmers, although livestock guarding animals were believed to be somewhat effective.

\subsection{Members of the public}

Our sample of the Swedish public overall considered all proposed interventions as somewhat acceptable, i.e. no negative $\mathrm{OA}$ values (Fig. 2, Table A4). Most accepted were non-lethal interventions such as carnivore deterring fences, livestock guarding dogs, fladry, and sound deterrents. These were followed by hazing of carnivores and removal interventions. With the exception of carnivore deterring fences to protect sheep (Mann-Whitney $U$ test, $\mathrm{p}=.85$ ) and hazing of carnivores to protect reindeer (Mann-Whitney $U$ test, $\mathrm{p}=.90$ ), OA intention of the public was significantly different from the user groups in all cases (Mann-Whitney $U$ test, $\mathrm{p}<.05$ in all cases). The highest acceptance levels among members of the public were found for carnivore deterring fences to protect both sheep and reindeer, followed by sound deterrents to protect sheep, fladry to protect sheep, and livestock guarding dogs to protect sheep (Fig. 2). The potential for conflict was largest for removal interventions, followed by hazing of carnivores using snowmobile, and livestock guarding dogs to prevent attacks on sheep and free ranging livestock (Fig. 2, Table A4).

\subsection{General patterns}

For all user groups, accepted interventions were all believed to be somewhat effective, and interventions believed to be ineffective or counterproductive were opposed. A high level of believed effect does, however, not necessarily correspond to acceptance (interventions in quadrant IV, lower right, Fig. 1). In all user groups there appeared to be a greater overall consent for the believed effect of interventions than there was for accept intention. The PCI values were generally lower for believed effect than for oppose-accept intention. Hence, the PCI bubbles generally take an elliptical rather than a circular form. This indicates that other factors causes acceptance to vary, even when believed effect does not. In comparison to other interventions, the removal interventions were among the most accepted interventions in user groups, with the exception of pet dog owners who rated several dog training interventions higher. Among members of the public the pattern was reversed, and removal interventions were the least accepted.

\section{Discussion}

This study gives insights to how interventions, intended to reduce carnivore predation on domestic animals, are perceived by those who keep domestic animals and by the general the public. This is essential knowledge of the human dimensions that should be integrated into practice for optimisation of wildlife management decision processes to allow human-wildlife coexistence and conservation of debated species (Riley et al., 2002). Although the results are specific for our Swedish case study, we are also able to highlight relationships between acceptance and the believed effect of interventions which ought to be important considerations in all systems where wildlife conservation can generate negative impacts and conflicts. In an optimal situation, here illustrated by carnivore deterring fences for sheep, members of the public are in agreement with the user group in accepting the 
intervention. Animal owners and members of the public might also express similar, but slightly lower, levels of acceptance. This is illustrated in this study by hazing of carnivores using snowmobiles to protect reindeer. It is possible that reindeer herders and members of the public have similar underlying reasons for their acceptance of this intervention but we may also speculate that they do not. Levels of believed effect were higher than OA intention for hazing in both groups, but while it is possible that hazing represents an effort intense intervention for reindeer herders, it likely does not to members of the public. For members of the public the acceptance level of hazing is closest to that of carnivore removal. Interventions may spur ethical concerns and such can be the case with the removal of individuals in species of high conservation interest (Treves et al., 2016), perhaps similar concerns exist for hazing among members of the public. However, in the case of removal conflict may occur over the acceptability of intervention implementation (Vaske et al., 2010). Increased transparency and understanding for acceptance and opposition in stakeholder groups will be important to minimise the potential for conflict at intervention implementation. Not least can opposed interventions be avoided to minimise damage to the trust by animal owners in wildlife management (Simpson, 2007).

In our case study the dispersion in believed effect is relatively small within all groups, suggesting that respondents within user groups either have a similar knowledge of intervention effectiveness or make similar judgments of the effectiveness. The believed effect of an intervention, in some cases supported by scientific evaluations of effectiveness (van Eeden et al., 2018; Eklund et al., 2017), appears to be an important prerequisite for intervention acceptance in our study. However, not all variation in acceptance can be attributed to the believed effect of interventions. Providing evidence of effectiveness may thus not accurately address conflicts between conservation interests and animal husbandry, and could potentially even generate conflict (Redpath et al., 2015). Interventions such as livestock guarding animals and night shelters for transhumance livestock and sheep, or reindeer calving in enclosures, are examples of interventions that are believed effective but have a high dispersion and low central tendency for acceptance. In free text responses the user groups raise concerns for implications such as major economic costs and intense work effort as well as grave concerns for compromised animal welfare and health. These interventions additionally appear to suffer norm incompatibility with regard to land use and formal legislation.

When the dispersion and the central tendency of acceptance are low, there may be implications associated with the intervention that most users expect to suffer. On the other hand, where we find a high within-group PCI on acceptance, managers should be aware that it will be difficult to make assumptions about how an individual animal owner would respond to the implementation or suggestion to use the intervention. The higher PCI values suggest that when it comes to intervention use, it is not a case of "one intervention fits all" and that the intervention can be implemented by some owners whilst others struggle to cope with the associated implications. For successful use of interventions it is important to understand the individual owner's goals and needs before implementing or even suggesting an intervention. Communication between managers and animal owners will be essential.

In the end, members of the public as well as animal owners accepted the majority of suggested interventions. Some interventions are even more acceptable to users than would be expected from their believed effect. This may be illustrated by the acceptance of carnivore removal interventions among hunters. It is possible that these interventions bring additional benefits to hunters besides preventing attacks on their dogs, perhaps by providing new hunting opportunities and a reduced competition for game animals. However, there are also examples of opposed interventions. For instance, suggesting a change of dog breed to owners that have already decided on the type of dog they wish to keep, may fail to mitigate conflict levels over carnivore management.
When it comes to believed effect, most suggested interventions are believed to be somewhat effective. Again, there are important exceptions. One example is the wolf deterring bell, an intervention which hunters believe to be counter-productive and thus oppose. This is an intervention which has been supplied by the Swedish wildlife managing authorities free of charge as a service to hunters, but which is referred to as "tomfoolery" and a "food bell for wolves" in free text responses. We could speculate that active promotion of this intervention may not improve hunter trust in carnivore management.

In comparison to other animal owners, reindeer herders find themselves in a particularly vulnerable situation, as reindeer represent the main prey of large carnivores in northern Sweden (Mattisson et al., 2016; Pedersen et al., 1999). While other domestic animals suffer losses that could theoretically be prevented without major influence on the carrying capacity of carnivore populations (Frank et al., 2018), prevention of predation on reindeer would imply that carnivores must either switch to an alternative prey, or go without food. With the current prey availability in the region, omnivorous bears may adapt their diet if non-lethal interventions are successful, whilst obligate carnivores rely on reindeer husbandry and may be highly motivated to overcome non-lethal interventions to feed. It may thus be unsurprising to currently find removal interventions representing reductions in carnivore numbers as the most accepted interventions among reindeer herders. This is also indicated by the respondents in the optional free text responses, where reductions in carnivore population sizes are mentioned as the only truly effective interventions to reduce reindeer losses, although some reindeer losses are tolerated for carnivore conservation purposes. On the contrary, for members of the public, removal interventions clearly create ambivalence in the group, likely reflecting different views or norms on hunting activities and conservation priorities within this group. The implementation of these interventions could therefore have a potential to generate conflict between the user groups and the public.

We used a web-based survey to reach our respondents, as internet use in Sweden is high ( $93 \%$ of the population having internet access at home according to Statistics Sweden, 2016). In comparison to previous mail surveys on similar topics in Sweden, our response rates in this study were lower, but this may be expected for web-based surveys (Fan and Yan, 2010). One reason for variation is that populations may differ in confidence of using the online technology (Shih and Fan, 2008). If technology confidence transfers to other fields, our sample may be more comfortable with the use of technological interventions to prevent carnivore attacks. However, we may also assume that there would be a higher motivation to respond to the survey among those with stronger negative opinions about intervention use. We received fewer responses from reindeer herders than from other groups, which likely reflect difficulties in reaching herders with personal email. Similar to previous studies, we observed slightly higher response rates among hunters in comparison to other groups (Ericsson and Heberlein, 2003) which could relate to the relevance of the survey being perceived differently between groups.

Providing scientifically valid knowledge of intervention effectiveness has previously been highlighted as an important step for cost effective use of interventions in carnivore conservation and management (van Eeden et al., 2018; Eklund et al., 2017; Treves et al., 2016). Strong evaluations may be needed to justify the use of controversial interventions and could play an important role for the acceptability of interventions by increasing their associated believed effect. As the evidence base is currently small (Eklund et al., 2017; Treves et al., 2016), it is difficult for animal owners, members of the public, and managers alike to make judgements for intervention use. For future prioritisation of research and implementation of interventions, we can now highlight the essentiality of also considering end-user acceptance of interventions - interventions that are opposed may be unused and thereby useless even with evidence of effectiveness. Despite the current lack of research, decisions of intervention use must be taken every day where 
wildlife impact human livelihoods. Within the framework of adaptive wildlife management, the use of interventions should be continuously evaluated for biological effectiveness and implication as well as the human dimensions. Stakeholders need to be involved at an early stage (Redpath et al., 2013) to identify the goals and impacts of interventions to be evaluated (Riley et al., 2002), and stakeholder involvement is necessary to increase the acceptance of research results and implementation of interventions in the future.

A final important conclusion of this study is that the general public appears to believe in the effect of the proposed interventions and does not strongly oppose their use. This gives managers, researchers, and stakeholders, some space to work with the interventions considered most feasible and effective from the specific situations. Although the animal owners represent minorities of the general public, they can have a strong voice in carnivore management and policy making. Importantly, they represent the stakeholders that are directly affected by negative impacts of carnivore attacks and interventions to prevent attacks. Thus they become the central stakeholders in this context (Riley et al., 2002). Conflict with animal owners over intervention use may be avoided if active promotion of opposed interventions, and interventions with a higher potential for conflict, is dampened. This applies whether intervention use is promoted by managers, authorities, and researchers, or by owner organisations themselves. A wise use of interventions could reduce the risk of adding to the conflict over carnivore conservation, and increase the potential for coexistence between humans and wildlife.

\section{Role of the funding source}

The scientific work was funded by the Swedish Research Council for Environment, Agricultural Sciences, and Spatial Planning (FORMAS) and the Swedish Wildlife Damage Centre at the Swedish University of Agricultural Sciences. The funding sources had no role in in study design; in the collection, analysis and interpretation of data; in the writing of the report; and in the decision to submit the article for publication.

\section{Declaration of Competing Interest}

The authors have no conflicts of interest to disclose.

\section{Acknowledgements}

The Swedish Research Council for Environment, Agricultural Sciences, and Spatial Planning (FORMAS) and the Swedish Wildlife Damage Centre at the Swedish University of Agricultural Sciences provided funding for this project. The authors wish to thank Heather Hemmingmoore for creating the original carnivore distribution maps which we modified and include in the supplementary materials. Silhouettes in our main figures are modified or original images from Pixabay www.pixabay.com, used under the Creative Commons agreement.

\section{Appendix A. Supplementary data}

Supplementary data associated with this article can be found, in the online version, at http://dx.doi.org/10.1016/j.biocon.2019.108251.

\section{References}

Bruskotter, J.T., Schmidt, R.H., Teel, T.L., 2007. Are attitudes toward wolves changing? A case study in Utah. Biol. Conserv. 139, 211-218.

Davis, F.D., 1989. Perceived usefulness, perceived ease of use, and user acceptance of information technology. Mis Q. 13, 319-340.

van Eeden, L., Eklund, A., Miller, J.R.B., López-Bao, J.V., Chapron, G., Cejtin, M.R., Crowther, M.S., Dickman, C.R., Frank, J., Krofel, M., Macdonald, D.W., McManus, J., Meyer, T.K., Middleton, A.D., Newsome, T.M., Ripple, W.J., Ritchie, E.G., Schmitz, O.J., Stoner, K.J., Tourani, M., Treves, A., 2018. Carnivore conservation needs evidence-based livestock protection. PLoS Biol. 16 (9), e2005577.

Eklund, A., López-Bao, J.V., Tourani, M., Chapron, G., Frank, J., 2017. Limited evidence on the effectiveness of interventions to reduce livestock predation by large carnivores. Sci. Rep. 7 , 2097.

Ericsson, G., Heberlein, T.A., 2003. Attitudes of hunters, locals, and the general public in Sweden now that the wolves are back. Biol. Conserv. 111, 149-159.

Eythórsson, E., Tombre, I.M., Madsen, J., 2017. Goose management schemes to resolve conflicts with agriculture: theory, practice and effects. Ambio 46, 231-240.

Fan, W., Yan, Z., 2010. Factors affecting response rates of the web survey: a systematic review. Comput. Human Behav. 26, 132-139.

Fox, A.D., Madsen, J., 2017. Threatened species to super-abundance: the unexpected international implications of successful goose conservation. Ambio 46, 179-187.

Frank, J., Månsson, J., Höglund, L., 2018. Viltskadestatistik 2017 Skador av fredat vilt på tamdjur, hundar och gröda. Rapport från Viltskadecenter. SLU 1 2018, [in Swedish]

Frank, J., Johansson, M., Flykt, A., 2015. Public attitude towards the implementation of management actions aimed at reducing human fear of brown bears and wolves. Wildlife Biol. 21, 122-130.

Gigliotti, L., Decker, D.J., Carpenter, L.H., 2000. Developing the wildlife stakeholder acceptance capacity concept: research needed. Hum. Dimens. Wildl. 5, 76-82.

Gompper, M.E., 2002. Top carnivores in the suburbs? Ecological and conservation issues raised by colonization of North-eastern North America by Coyotes: the expansion of the coyote's geographical range may broadly influence community structure, and rising coyote densities in the suburbs may alter how the general public views wildlife. BioScience 52, 185-190.

Højberg, P.L., Nielsen, M.R., Jacobsen, J.B., 2017. Fear, economic consequences, hunting competition and distrust of authorities determine preferences for illegal lethal actions against gray wolves (Canis lupus): a choice experiment among landowners in Jutland. Denmark. Crime, Law, and Society 67, 461-480.

Lemon, J., 2006. Plotrix: a Package in the Red Light District of R.R-News, vol. 6. pp. 8-12.

Lute, M.L., Carter, N.H., López-Bao, J.V., Linnell, J.D.C., 2018. Conservation professionals agree on challenges to coexisting with large carnivores but not on solutions. Biol. Conserv. 218, 223-232.

MacMillan, D., Hanley, N., Daw, M., 2004. Costs and benefits of wild goose conservation in Scotland. Biol. Conserv. 119, 475-485.

Manfredo, M.J., Vaske, J.J., Teel, T.L., 2003. The potential for conflict index: a graphic approach to practical significance of human dimensions research. Hum. Dimens. Wildl. 8, 219-228.

Mattisson, J., Odden, J., Nilsen, E.B., Linnell, J.D.C., Persson, J., Andrén, H., 2011. Factors affecting Eurasian lynx kill rates on semi-domestic reindeer in northern Scandinavia: Can ecological research contribute to the development of a fair compensation system? Biol. Conserv. 144, 3009-3017.

Mattisson, J., Rauset, G.R., Odden, J., Andrén, H., Linnell, J.D.C., Persson, J., 2016. Predation or scavenging? Prey body condition influences decision-making in a facultative predator, the wolverine. Ecosphere 7. https://doi.org/10.1002/ecs2.1407.

Needham, M.D., Vaske, J.J., Manfredo, M.J., 2004. Hunters' behavior and acceptance of management actions related to chronic wasting disease in eight states. Hum. Dimens. Wildl. 9, 211-231.

Okello, M.M., 2006. Land use changes and human-wildlife conflicts in the Amboseli area. Kenya. Human Dimensions of Wildlife 10, 19-28.

Pedersen, V.A., Linnell, J.D.C., Andersen, R., Andrén, H., Lindén, M., Segerström, P., 1999. Winter lynx Lynx lynx predation on semi-domestic reindeer Rangifer tarandus in northern Sweden. Wildlife Biol. 5, 203-211.

Redpath, S.M., Bhatia, S., Young, J., 2015. Tilting at wildlife: reconsidering human-wildlife conflict. Oryx 49, 222-225.

Redpath, S.M., Young, J., Evely, A., Adamas, W.M., Sutherland, W.J., Whitehouse, A., Amar, A., Lambert, R.A., Linnell, J.D.C., Watt, A., Gutiérrez, R.J., 2013. Understanding and managing conservation conflicts. Trends Ecol. Evol. 28 (2), 100-109.

Riley, S.J., Decker, D.J., Carpenter, L.H., Organ, J.F., Siemer, W.F., Mattfeld, G.F., Parson, G., 2002. The essence of wildlife management. Wildl. Soc. Bull. 30, 585-593.

Sharp, R.L., Larson, L.R., Green, G.T., 2011. Factors influencing public preferences for invasive alien species management. Biol. Conserv. 144, 2097-2104.

Shih, T., Fan, X., 2008. Comparing response rates from web and mail surveys: a meta-analysis. Field methods 20, 249-271.

Shivik, J.A., 2006. Tools for the Edge: what's new for conserving carnivores. BioScience 56 253-259.

Simpson, J.A., 2007. Psychological foundations of trust. Curr. Dir. Psychol. Sci. 16, 264-268.

Sweden, Statistics, 2016. Use of Computers and the Internet by Private Persons in 2016. ISSN 1654-7624 [in Swedish].

Tchamba, M.N., 1996. History and present status of the human/elephant conflict in the WazaLogone region, Cameroon, West Africa. Biol. Conserv. 75, 35-41.

Teel, T.L., Manfredo, M.J., 2010. Understanding the diversity of public interests in wildlife conservation. Conserv. Biol. 24, 128-139.

Treves, A., Krofel, M., McManus, J., 2016. Predator control should not be a shot in the dark. Front. Ecol. Environ. 14, 380-388.

Treves, A., Karanth, K.U., 2003. Human-carnivore conflict and perspectives on carnivore management worldwide. Conserv. Biol. 17, 1491-1499.

Vaske, J.J., Beaman, J., Barreto, H., Shelby, L.B., 2010. An extension and further validation of the Potential for Conflict Index. Leis. Sci. 32, 240-254.

Vaske, J.J., Needham, M.D., Newman, P., Manfredo, M.J., Petchenik, J., 2006. Potential for conflict index: hunters' responses to chronic wasting disease. Wildl. Soc. Bull. 34, 44-50.

Westerberg, H., Lunneryd, S.-G., Fjälling, A., Wahlberg, M., 2006. Reconciling fisheries activities with the conservation of seals throughout the development of new fishing gear: a case study from the baltic fishery - gray seal conflict. American Fisheries Society Symposium 2006.

Wickens, P.A., Japp, D.W., Shelton, P.A., Kriel, F., Goosen, P.C., Rose, B., Augustyn, C.J., Bross, C.A.R., Penney, A.J., Krohn, R.G., 1992. Seals and fisheries in South Africa - competition and conflict. South Afr. J. Mar. Sci. 12, 773-789.

Williams, A.C., Johnsingh, A.J.T., Krausman, P. R., 2001. Elephant-human conflicts in Rajaji National Park, north western India. Wildl. Soc. Bull. 29, 1097-1104. 